\title{
A REVIEW OF RECORDING TECHNOLOGIES FOR DIGITAL FABRICATION IN HERITAGE CONSERVATION
}

\author{
A. Weigert ${ }^{1}$, A. Dhanda ${ }^{1}$, J. Cano ${ }^{2}$, C. Bayod ${ }^{2}$, S. Fai ${ }^{1}$, M. Santana Quintero ${ }^{1}$ \\ ${ }^{1}$ Carleton Immersive Media Studio (CIMS), Carleton University, Ottawa, Canada - (aweigert, adhanda, sfai)@ cims.carleton.ca, \\ (mario.santana)@carleton.ca \\ ${ }^{2}$ Factum-Arte, Madrid, Spain
}

\section{Commission II}

KEY WORDS: Digital Fabrication, Digital Documentation, Photogrammetry, Laser Scanning, 3D scanner, 3D Printing, CNC, Heritage Conservation

\begin{abstract}
:
Digital tools have brought new techniques for recording and fabrication allowing for the augmentation of traditional processes in repairs and restorations. Traditional mechanical and chemical techniques require physical contact to the artefacts of interest, while LiDAR Scanning, photogrammetry and structured light scanning provide non-invasive solutions. Analog recording technologies have always informed fabrication processes, but contemporary digital recording can produce complete geometry for fabrication. In this paper, we discuss recording and fabrication technologies and how they have been applied for heritage conservation.
\end{abstract}

\section{ANALOG TECHNIQUES}

For architectural purposes, traditional survey instruments were comprised mainly of optical lenses and levels with measurement rules. Triangulation could be used to measure coordinates with intersecting angular measurements while trilateration used only distance measurements (Gorse et al., 2012). A hybrid of these techniques and tools were used before digital total stations and 3D laser scanners. The measurements from these techniques were used in analog and digital architectural design and fabrication. The pointing machine is a 3D measurement tool traditionally used by Greek and Roman sculptors to create facsimiles. It is comprised of a cage built around a sculpture; the frame was used as a reference for measuring key points on the sculpture (Clarke and Clarke, 2010). The pantograph is traditional a tool used by artists, draughtsman and technical designers to create scaled up or down copies of drawings (Ward, 2008). 3D versions of the pantograph are used by sculptors to create a scaled-up model of their maquettes. It was a tool for producing facsimiles via mechanically-assisted fabrication.

\section{DIGITAL RECORDING}

\subsection{Photogrammetry}

Structure from motion (SfM) photogrammetry is a method of automatically reconstructing 3D geometry from a series of overlapping photos with varying camera positions and angles relative to an object or surface (Stylianidis and Remondino, 2008). It is a popular and practical tool for documenting geometry from macro to micro scales. Photogrammetry has the flexibility of use with a handheld SLR camera and with unmanned aerial vehicles (UAV). Photogrammetry is a metrological tool used in many industries including the automotive, machine, shipbuilding, aerospace, architecture, heritage conservation, archaeology, civil, medicine physiology, forensics, and natural sciences (Luhmann, et al., 2011)

\subsection{Hand Laser Scanning}

Hand laser scanners employ triangulation-based measurement from a movable handheld device. The position of the scanner was determined real-time using either a mechanical arm or fixed targets on the scanned object. Hand scanners are already popular in rapid prototyping, archiving, archaeological, and metrological applications (Stylianidis and Remondino, 2008).

\subsection{Lucida Scanner}

The Lucida is a 3D scanning system, realized by artist/engineer Manuel Franquelo, built by Factum-Arte and supported by the Factum Foundation. The scanner was designed to record micro surface details of painting and relief surfaces. In its most recent form, the Lucida Scanner is a stereo camera, laser hybrid system with automatic $\mathrm{X}$ and $\mathrm{Y}$ control and additional manual $\mathrm{Z}$ control. This configuration is able to record texture resolutions up to 100 microns across challenging shiny, glossy, matte, or dark textures (Factum Foundation, 2017).

\subsection{Terrestrial Laser Scanning}

Terrestrial laser scanning involves emitting laser light (typically) from a fixed position to obtain a ranged measurement. Terrestrial scanner technology is delineated into three main categories: pulse-based, phase-based and triangulation-based scanners. The pulse-based scanners use the emitted-reflected light time delay as the basis of their measurement. Phase-based scanners use the lasers sinusoidal wave shift as a basis of their measurement. Triangulation-based scanners use the baseline between laser emitter and camera to triangulate a measurement (Stylianidis and Remondino, 2008). We differentiate between hand scanning and laser scanning by whether the device is mounted on a tripod. 
The International Archives of the Photogrammetry, Remote Sensing and Spatial Information Sciences, Volume XLII-2/W9, 2019 8th Intl. Workshop 3D-ARCH “3D Virtual Reconstruction and Visualization of Complex Architectures”, 6-8 February 2019, Bergamo, Italy

\begin{tabular}{|c|c|c|c|c|c|c|}
\hline Techniques & Cpst & $\begin{array}{l}\text { Ease } \\
\text { of use }\end{array}$ & $\begin{array}{l}\text { Geometric } \\
\text { freedom }\end{array}$ & $\begin{array}{c}\text { Material } \\
\text { adequacy to } \mathrm{CH}\end{array}$ & Precision & $\begin{array}{l}\text { Working } \\
\text { size }\end{array}$ \\
\hline \multicolumn{7}{|l|}{ Subtractive Techniques } \\
\hline 2.5D CNC Carving & low/medium & low & low & high & high & $\mathrm{mm}$ to $\mathrm{m}$ \\
\hline 6-Axis CNC Carving & high & very low & medium & high & high & $\mathrm{mm}$ to $\mathrm{m}$ \\
\hline \multicolumn{7}{|l|}{ Additive Techniques } \\
\hline FDM & very low/medium & medium/high & medium & low & medium/high & $\mathrm{cm}$ to $\mathrm{dm}$ \\
\hline LOM & medium & medium & low & medium & medium & $\mathrm{cm}$ to $\mathrm{dm}$ \\
\hline Gypsum binding & medium & medium & very high & medium/high & medium/high & $\mathrm{cm}$ to $\mathrm{dm}$ \\
\hline Metal Sintering & very high & low & very high & medium & medium/high & $\mathrm{mm}$ to $\mathrm{cm}$ \\
\hline Plastic Sintering & very high & medium & very high & medium & medium/high & $\mathrm{mm}$ to $\mathrm{dm}$ \\
\hline Photopolymerization & high & medium/high & medium & low & high/very high & $\mathrm{mm}$ to $\mathrm{dm}$ \\
\hline
\end{tabular}

Table 1. Summary of fabrication techniques for cultural heritage (Scopigno et al 2017)

\section{DIGITAL RECORDING FOR FABRICATION}

Scopigno et al 2017, conducted a survey in digital fabrication techniques for cultural heritage, where they look at the distinctions, strengths, limitations and costs of the available fabrication technologies. It is important to understand the difference between subtractive and additive techniques; the former removes material and the latter builds up material to a specified form. Their work is summarized in table 1; comparing the difference between the different types of printing (additive) and milling (subtractive) fabrication tools. We are specifically interested in documenting how people have used digital recording techniques to fabricate. We categorize our findings based on what recording technique used in their work.

\subsection{Photogrammetry}

Hayes et al. 2015, used photogrammetry and handheld scanning to digitize stone decayed sculptural elements on the Canadian parliament buildings. They used the photogrammetric data to fabricate 1:1, as-found maquettes from high density foam with a 3 -axis CNC router. Their final model was milled from stone with a 6-axis robotic arm and hand finished by Phil White, the Dominion Sculptor of Canada. They categorize this process as Digitally-Assisted Fabrication; using digital tools to augment the work of the craftsman.

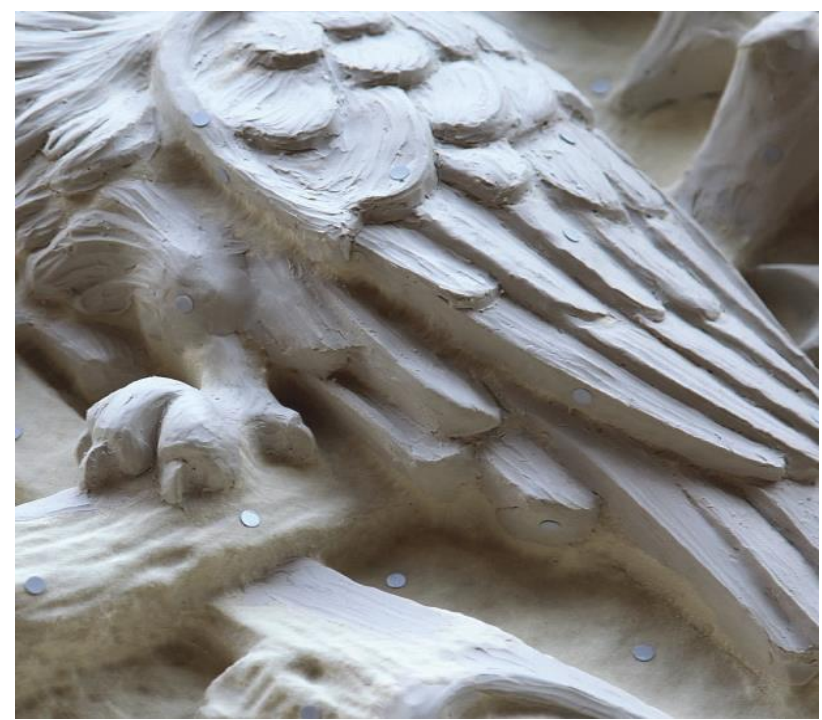

Figure 1. Repaired foam maquette (Hayes et al. 2015)
Percy et al. 2017, used the Digitally-Assisted Fabrication method, developed in Hayes et al. 2015, to mill a design test for the new Chamber of the Senate of Canada. The project is not directly for heritage, but it is as a result of the rehabilitation of the Centre Block. Phil White, the Dominion Sculptor of Canada, carved ten species of maple leaves in medium density urethane foam. These carved leaves were digitized using photogrammetry and then arranged digitally to create the final composition. A 6-axis robotic arm was used to mill the final composition in wood.

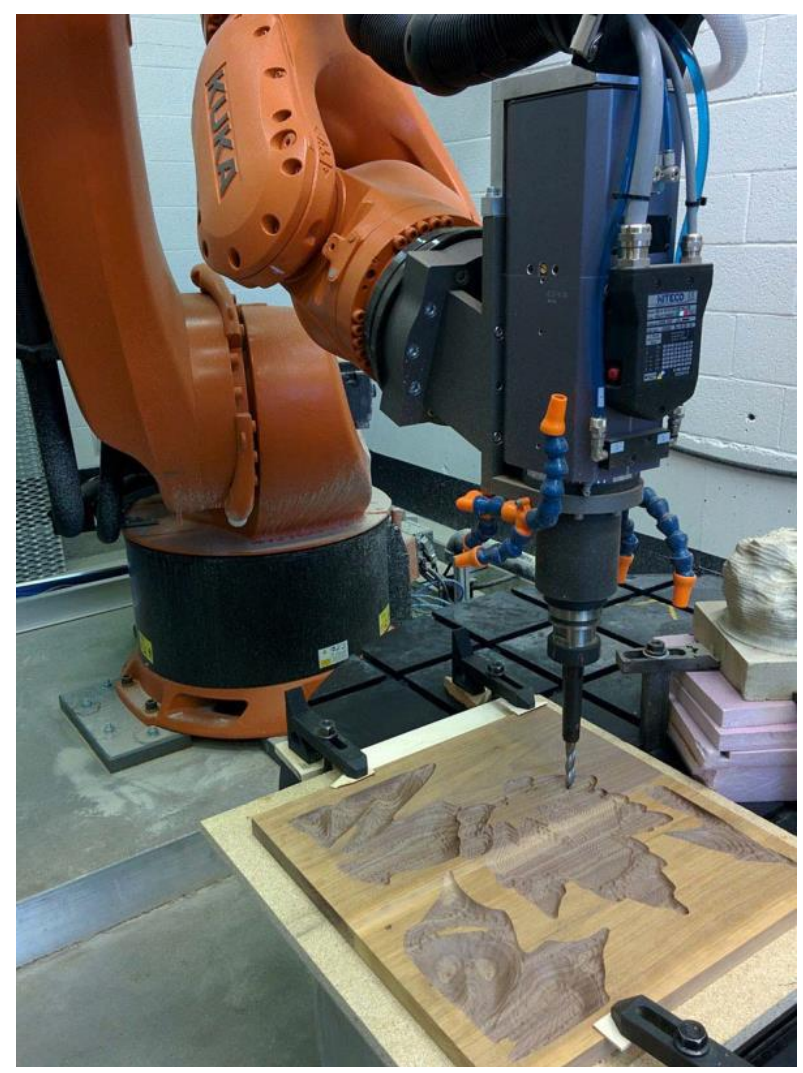

Figure 2. Milling a test piece of walnut using the KR360 (Percy et al. 2017)

Ackermana and Glekasb 2017, used photogrammetry to measure the existing conditions of the Larz Anderson Estate (now Larz Anderson Park). The photogrammetric model is used 
as a reference to make interpretations of previous states of the site. Other records like historic architectural drawings and photographs are used to reconstruct significant iterations of the site. Each iteration is 3D printed as a scale model.

Romero and Bustamante, 2017 documented how architectural details can be replaced based on geometry captured from photogrammetry. A deteriorated architectural spandrel was the focus of this project; the spandrel was a repeating element on the building and could be replaced based on their geometry. A version of the spandrel was CNC milled from low-density foam, then sanded and coated with polyurethane for strength. This fabricated spandrel was used to create a rubber mould to create replacement Cast-stone spandrels.

Apollonio et al. 2017 leveraged photogrammetry in multiple applications for the restoration of Bologna's Neptune Fountain. They captured accurate and detailed geometric and colour data for surface cleaning analysis, planning new water system and jets, lighting design simulation, structural analysis, visualization/renderings, and 3D printing to repair holes and missing elements. They were able to capture the complex geometry of the sculpture and the damages in order to $3 \mathrm{D}$ print new repair elements with a precise fit.

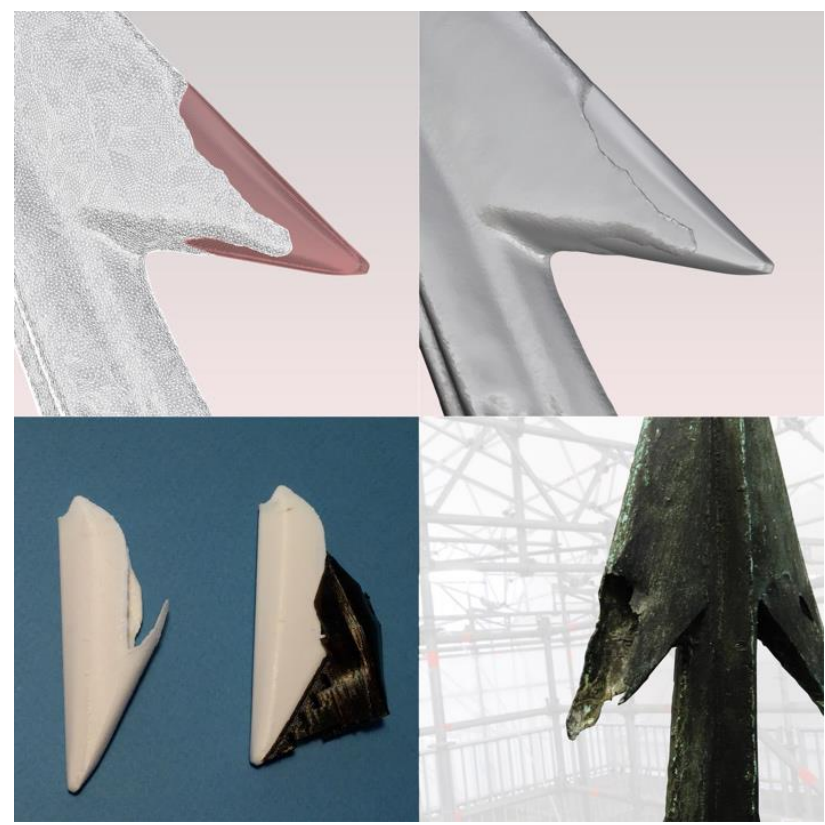

Figure 3. 3D Print repair for sculpture (Apollonio et al. 2017)

Tousant 2018, applied underwater photogrammetry to capture geometry of flooded barn foundations. He was also able to 3D resin print a scale model of the lost cultural site. He also conducted a speculative reconstruction of the barn based on the foundation geometry and existing barn scans.

\subsection{Hand Laser Scanning}

Tucci and Bonora 2007, used a hand scanning coordinate measurement machine (CMM) hybrid to extract geometry from a sculpture of The Prophet. CMM's require contact and are not preferred for recording delicate objects; however, Tucci and Bonora's system used the CMM to measure the position and orientation of the hand scanner. They tested milling a replica of the statue from polystyrene and $3 \mathrm{D}$ printing the head from ABS.

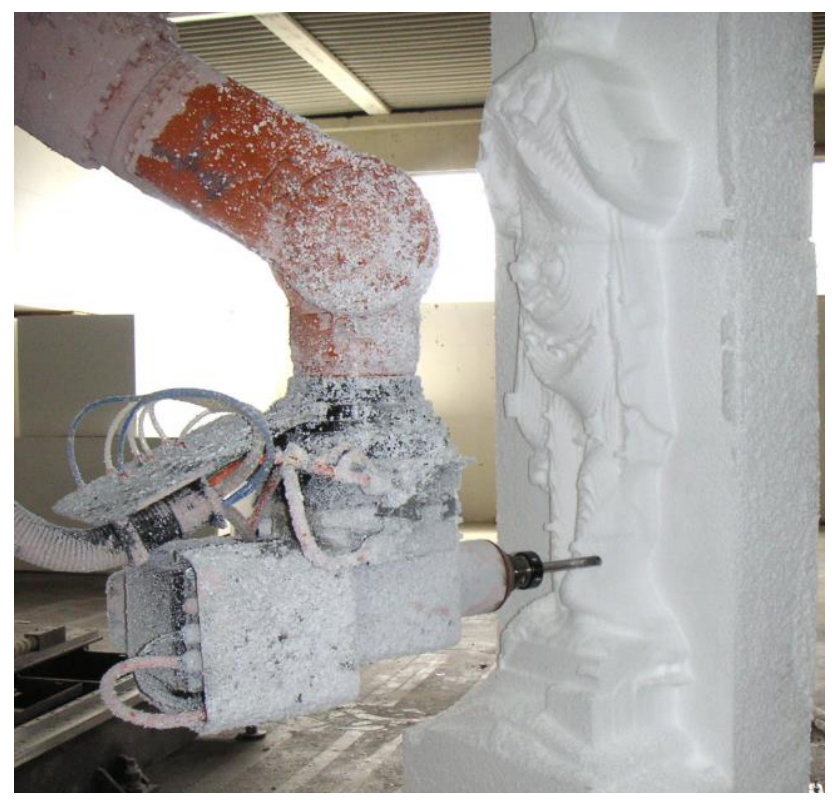

Figure 4. Robotic milling of statue from polystyrene (Tucci and Bonora 2007)

Bates 2013, documented the use of laser scanning technology for the fabrication of cast iron components replaced in a New York City Cast-Iron Loft restoration. A handheld laser scanner was used to gather existing conditions of heavily damaged castiron structural components. They used the captured geometry to create new casting moulds for a traditional moulding process. New cast-iron pieces based on the captured geometry were used to repair the damaged elements in the restoration.

\subsection{Lucida Scanning}

The Lucida Scanner results are used to recreate micro surface details with a CNC machine. Factum-Arte has also conducted tests comparing photogrammetry and terrestrial LiDAR scanners with The Lucida Scanner. The Factum Foundation used The Lucida scanner for multiple fabrication applications; the most distinct project was their scan and facsimile of a section of Tomb of Seti I. Their facsimile is to be used for training Egyptian conservationists. They have also scanned, digitally restored and produced facsimiles of many paintings (Factum Foundation, 2017).

\subsection{Terrestrial Laser Scanning}

Smith et al. 2012, explore how laser scanning could augment their project on the restoration of the Prudential Lions in Branch Brook Park, New Jersey. To repair deteriorated areas of the lions, conservators and sculptors restored details with clay. The restored sculptures were recorded with a Surphaser ${ }^{\circledR}$ 25HSX, a phase shift, hemispherical 3D scanner. From the captured geometry, a five-axis CNC was used to mill segments of the sculptures from medium-density foam. Once the segments were glued together, the conservators and sculptors finished the surfaces; removing digital anomalies while referencing historic photographs. These finished replicas were 


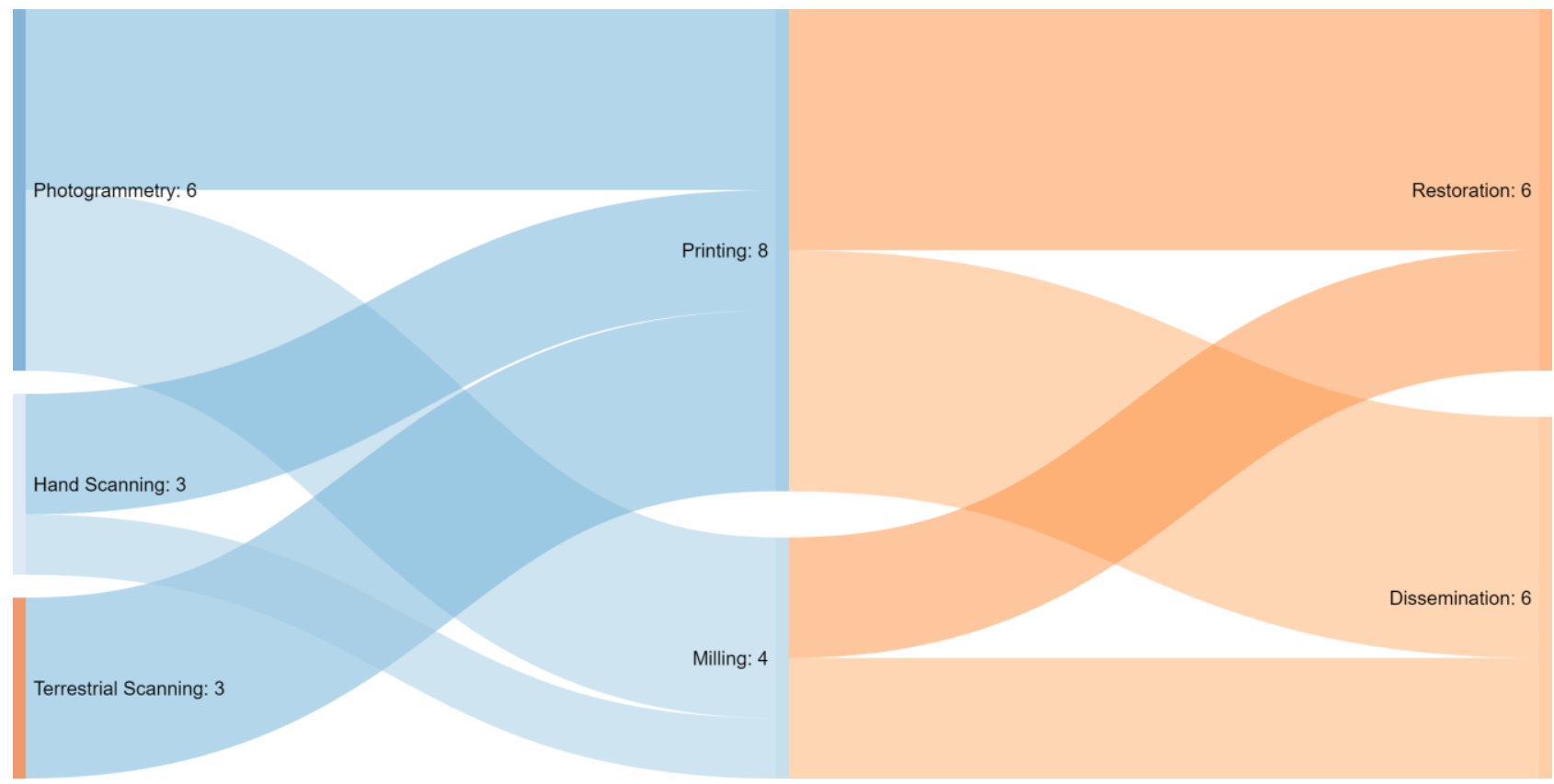

Figure 5. Sankey diagram of digital tools and applications (Bogart, S. (n.d.))

used to create casting moulds in order to protect the original statues. Two precast concrete replicas replaced the originals in Branch Brook Park, while the originals were moved to the Newark Hall of Records.

Arbace et al. 2013, used the Konica Minolta Vivid 910 laser scanner in the restoration of the Madonna of Pietranico, a terracotta statue fragmented by an earthquake. The Konica Minolta Vivid 910 is a tripod-mounted, triangulation-based laser scanner; it was able to accurately capture the geometry of the sculpture's 24 fragments at about half millimeter resolution. Expert conservators held two fragments in alignment while being scanned in order to aid the digital reassembly. One digitally reassembled, they were able to remodel missing areas and an internal structure to support the physical fragments. 2D drawings of some modelled missing areas were created for a sculptor to create new terracotta fragments by hand. Portions of the interior support structure were $3 \mathrm{D}$ printed from a glued powder.

Before sections of the Tomb of Seti I was recorded, FactumArte compared results between The Lucida Scanner and The Faro Focus 3DX 330 - a phase shift light radar scanner. They found the LiDAR scanner can record high resolution geometry but with an inherent noise. The scanner was best utilized for providing a medium resolution geometry and colour info for the entire space. The processed LiDAR scan data was also fused with photogrammetry in photogrammetry processing software (Lowe, 2017).

Ballarin et al. 2018, look at how 3D printing collides with the museum experience. They used a Konika Minolta Range 7 triangulation scanner to digitize an archaeological finding of a centimeter sized engraved limestone slab. Four replicas of the engraved slab were 3D printed from different materials with selective laser sintering. Three copies were printed in nylon with different colours and rigidities and one copy was created from a sandstone powder that can be printed with variable colour. These replicas allow for people to interact with the objects more intimately than the originals. They understand the artefacts through more senses than just seeing the original. They also created a version in which the colour texture was used to augment the printed geometry.
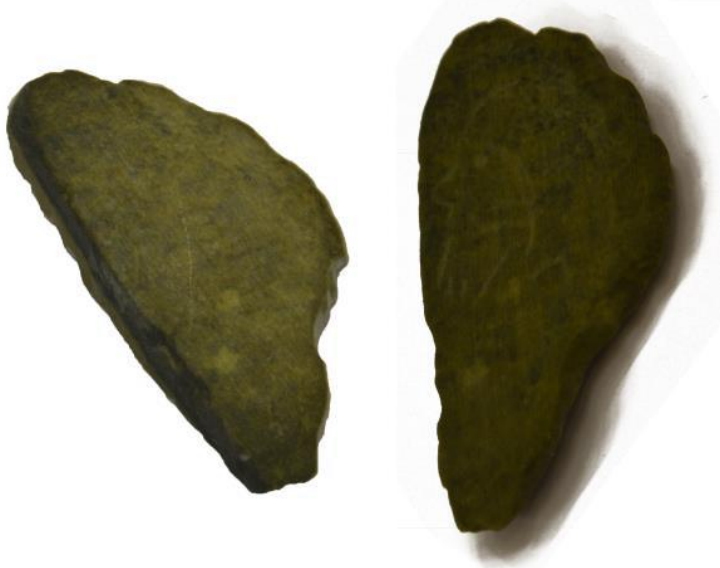

Figure 6. Comparison between the coloured 3D replica and the "augmented" one (Ballarin et al. 2018)

\section{DISCUSSION}

In the digital fabrication survey from Scopigno et al 2017, they discuss current and potential applications of fabrication for cultural heritage. They include: production of copies in any scale, supporting visually impaired people, temporary or permanent replacement of originals, temporary loan of artworks for temporary exhibitions, production of tailored packaging for shipping or displaying cultural objects, education and experimentation in museums, sensorized replicas in museums, and restoration. From reviewing the existing academic documentation, we can how people have been applying specific recording and fabrication techniques for heritage conservation. 
We use a Sankey diagram (figure 5) to illustrate how each of the techniques have been used in relation to each other and their applications. We simplified the applications into two categories: restoration and dissemination. Restoration encompasses any project that uses digital recording and fabrication to have a direct effect on the original sculptural element of concern, which includes repairs, replacements, and reconstruction. Dissemination is used to capture other applications including, education, augmentation, digital reconstruction and restitution.

\section{CONCLUSIONS}

This paper has presented a review of recording and fabrication technologies and how they have been applied for heritage conservation. Photogrammetry and laser scanning technologies paired with digital fabrication are useful tools in repairs, restorations, dissemination and augmentation of sculptural cultural heritage.

\section{ACKNOWLEDGEMENTS}

The authors wish to thank Factum-Arte and the Factum Foundation for their support. This work was supported by the NSERC Create Heritage Engineering grant at Carleton University.

\section{REFERENCES}

Ackermana, A., Glekasb, E., 2017. Digital Capture and Fabrication Tools for Interpretation of Historic Sites. Int. Annals of Photogrammetry, Remote Sensing \& Spatial Information Sciences, Vol. IV-2/W2, pp. 107-114.

Apollonio, F.I., Ballabeni, S., Bertacchi, S., Fallavollita, F., Foschi, R., Gaiani, M., 2017. From Documentation Images to Restauration Support Tools: A Path Following the Neptune Fountain in Bologna Design Process. Int. Archives of Photogrammetry, Remote Sensing \& Spatial Information Sciences, Vol. XLII-5/W1, pp. 329-336.

Arbace, L., Sonnino, E., Callieri, M., Dellepiane, M., Fabbri, M., Idelson, A.I., Scopigno, R., 2013. Innovative uses of 3D digital technologies to assist the restoration of a fragmented terracotta statue. Journal of Cultural Heritage, Vol. 14(4).

Ballarin, M., Balletti, C., and Vernier, P.: Replicas in Cultural Heritage: 3D Printing and the Museum Experience, Int. Arch. Photogramm. Remote Sens. Spatial Inf. Sci., XLII-2, 55-62, https://doi.org/10.5194/isprs-archives-XLII-2-55-2018, 2018.

Bates, R.C., 2013. Restoration of an Artist's Cast-Iron Loft Building in SoHo in New York City. APT Bulletin: The Journal of Preservation Technology, Vol. 44(4), pp. 39-43.

Bogart, S. (n.d.). SankeyMATIC A Sankey diagram builder for everyone. Retrieved December 21, 2018, from http://sankeymatic.com/

Clarke, M., Clarke, D., 2010. pointing machine. The Concise Oxford Dictionary of Art Terms, Oxford University Press.

Factum Foundation, 2017. The Lucida 3D Scanner: A Manual. Factum-Arte \& Factum Foundation.
Fatuzzo, G., Mussumeci, G., Oliveri, S. M., \& Sequenzia, G. 2011. The "Guerriero di castiglione": Reconstructing missing elements with integrated non-destructive 3D modelling techniques. Journal of Archaeological Science, 38(12), 35333540. doi:10.1016/j.jas.2011.08.016

Gorse, C., Johnston, D., Pritchard, M., 2012. Dictionary of Construction, Surveying and Civil Engineering, Oxford University Press.

Hayes J., Fai, S., Kretz, S., Ouimet, C., White, P., 2015. Digitally-Assisted Stone Carving of a Relief Sculpture for the Parliament Buildings National Historic Site of Canada. Int. Archives of Photogrammetry, Remote Sensing \& Spatial Information Sciences, Vol. II-5/W3, pp. 97-103.

Lowe, A., 2017. Scanning Seti: The Re-Generation of a Pharaonic Tomb 200 Years in the Life of a Tomb. Factum-Arte \& Factum Foundation, http://www.factumarte.com/resources/files/ff/articles/seti_basel_36.pdf (Last accessed December 2018).

Luhmann, T., Robson, S., Kyle, S., Harley, I., 2011. Close Range Photogrammetry, Principles, Techniques and Applications, Whittles Publishing.

Oxford University Press, n.d.. thing, https://en.oxforddictionaries.com/definition/thing (Last accessed December 2018).

Percy, K., Fai, S., Hayes, J., White, P., Ouimet, C., 2017. Real//Virtual//Real, or, Aibohphobia (The Phobia of Palindromes). 23rd International Conference on Virtual System \& Multimedia (VSMM).

Romero, D., \& Bustamante, A., 2017. Photogrammetry as a Tool to Replace Eroded Decorative Architectural Elements. APT Bulletin: The Journal of Preservation Technology, Vol. 48(1), pp. 15-22.

Scopigno, R., Cignoni, P., Pietroni, N., Callieri, M., Dellepiane, M., 2014. Digital Fabrication Technologies for Cultural Heritage (STAR). Computer Graphics Forum, Vol. 36(1).

Scopigno, R. , Cignoni, P. , Pietroni, N. , Callieri, M. and Dellepiane, M. (2017), Digital Fabrication Techniques for Cultural Heritage: A Survey. Computer Graphics Forum, 36: 621. doi:10.1111/cgf.12781

Smith, C., Kreilick, T.S., Abramson, H., Woodburn G., and Lash, G., 2012. Restoring The Lions' Roar: Documenting And Replicating Limestone Sculptures Through Laser Scanning, 3D Modeling, \& CNC Machining, 3D Digital Documentation Summit.

Stylianidis, E., Remondino, F., 2008. 3D Recording, Documentation and Management of Cultural Heritage. Whittles Publishing, pp 253-368.

Tousant, K., In Press. Learning to Dive The Digital Restitution of Lot 3317. Carleton Faculty of Graduate and Postdoctoral Affairs. 
Tucci, G., Bonora, V., 2007. Application of High Resolution Scanning Systems for Virtual Moulds and Replicas of Sculptural Works. Int. Archives of Photogrammetry, Remote Sensing \& Spatial Information Sciences, Vol. XXXVI-5/C53.

Tucci, G., \& Bonora, V. (2012). from real to."real". a review of geomatic and rapid prototyping techniques for solid modelling in cultural heritage field. The International Archives of the Photogrammetry, 575-582. doi:10.5194/isprsarchivesXXXVIII-5-W16-575-2011

Ward, G., 2008. The Grove Encyclopedia of Materials and Techniques in Art, Oxford University Press. 